\title{
Exploring Teachers' Experiences on the Nature of Mathematics based on their Curricular and Pedagogical Practices: A Phenomenological Inquiry
}

\author{
${ }^{7}$ Kathmandu University School of Education, NEPAL \\ *CORRESPONDENCE: $\bigotimes$ laxman17@kusoed.edu.np
}

Laxman Luitel ${ }^{1 *}$

\begin{abstract}
The school mathematics curriculum development process in Nepal is still conventional. Contextualized mathematics teaching and learning has not been the priority of school education of Nepal. Majority of the school mathematics teachers in Nepal still conceptualize the mathematics and mathematics curriculum from the conformist approach. Thus, this paper aims to explore mathematics teachers' experiences on the nature of mathematics focusing on their curricular and pedagogical practices based on the research question how mathematics teachers experience the nature of mathematical knowledge during their curricular and pedagogical practices. Ernest's and Luitel's nature of mathematical knowledge has enabled me to evaluate teachers' experiences towards the nature of mathematical knowledge and Habermas's theory of knowledge constitutive interest has guided the research for knowledge and implied others' concept. The study has relied on the phenomenological approach and reflected the experiences of four mathematics teachers. The paper concludes that mathematics curriculum guided by emancipatory interest as well as practical interest promotes counter-hegemonic vision of teaching and learning mathematics and might develop critical consciousness. Critical consciousness embedded mathematics curriculum helps students and teachers to unpack the cultural nature of mathematics education and taken-for-granted assumptions about teaching and learning through critical pedagogy.
\end{abstract}

Keywords: Mathematics curriculum, pedagogy, phenomenology, absolutist nature, fallibilist nature

\section{INTRODUCTION}

The term curriculum in general and mathematics curriculum in particular, is commonly used in school education. Curriculum is taken as one of the most important resources of teaching and learning activities. It provides certain guidelines and layout of contents and pedagogical implications to students and teachers. Mathematics teachers develop an annual plan, unit plan and lesson plan on the basis of the curriculum. Thus, mathematics curriculum must have a place to incorporate students' experiences, prior knowledge as well as specific needs and interests. The school curriculum communicates what we choose to remember about our past, what we believe about the present, and what we hope for the future (Pinar, 2004). In this context, mathematics curriculum needs to give a space for students to reflect on their own past experiences, present practices, and create future goals. It must incorporate cultural artefacts, local as well as global practices of mathematics, real life problems, and also needs to give opportunities to reflect on their own practices.

Article History: Received 25 March $2020 \bullet$ Revised 23 June $2020 \bullet$ Accepted 23 August 2020

(C) 2020 by the authors; licensee Modestum. Open Access terms of the Creative Commons Attribution 4.0 International License (http://creativecommons.org/licenses/by/4.0/) apply. The license permits unrestricted use, distribution, and reproduction in any medium, on the condition that users give exact credit to the original author(s) and the source, provide a link to the Creative Commons license, and indicate if they made any changes. 
However, how is the mathematics curriculum designed? Whose involvement in curriculum development makes an effective curriculum? How are the contents selected and organized? Whose interest whether the students', teachers', or curriculum designers' is being served?, and so on kind of questions matter a lot to construct different natures of mathematics (absolutist, fallibilist, problem solving, and so on) and make teaching and learning mathematics effective.

In the context of Nepal, the mathematics curriculum design and development process is conventional. Mathematics curriculum is prepared by the Curriculum Development Center (CDC) and prescribed to the school and school teachers to implement. There is less involvement of schools' mathematics teachers and almost no involvement of students in the curriculum development process, thereby low possibility of incorporating the students' experiences, teachers' beliefs and ideas into the mathematics curriculum. Because of this top-down curriculum development process, most of the students, teachers as well as other stakeholders have experienced that the mathematics curriculum is culturally decontextualized (Luitel, 2018). Contextualized teaching and learning especially in mathematics has not been the priority of school education of Nepal. The priority is given to the algorithmic and routine problems included in the textbook during teaching and learning process and bounded inside the four walls of the classroom that leads students towards rote-memorization. Moreover, I agreed with Luitel (2013) as he experienced that mathematics in Nepal is taken as a vehicle for enhancing scientific and technological innovation by subscribing to a narrowly conceived notion of reform as simply adding more content area. Thus, despite various policy reforms, the majority of mathematics classroom culture and practices remain the same (Luitel \& Taylor, 2005).

Fortunately, in recent times, teacher educators in Nepal are trying to motivate mathematics teachers to revise the mathematics curriculum integrating other disciplines based on the school context, students' experiences, prior knowledge, available resources, and so on; and making aware of the student-centered pedagogy through Teacher Professional Development (TPD) program. The TPD program might have assisted the mathematics teachers to change their beliefs and perception (such as curriculum as an object or thing, curriculum as a textbook, and so on.) towards mathematics curriculum. Yet, de/contextualized nature of mathematics curriculum still prompts teachers to perceive the nature of mathematical knowledge in many ways, such as absolutist nature of mathematical knowledge and fallibilist nature of mathematical knowledge (Ernest, 1991), pure, impure as well as im/pure mathematical knowledge (Luitel, 2013), thereby in/directly influencing teaching and learning activity. The perception on the nature of mathematical knowledge held by the people or society has a major influence on the development of the school mathematics curriculum, instruction, and research (Dossey, 1992). Perceptions on the nature of mathematical knowledge and mathematics curriculum are created on the basis of their experiences on the pedagogical as well as curricular practices.

The paper aims to explore mathematics teachers' experiences about the nature of mathematics that are implicit in the Nepali schools' mathematics curriculum. Moreover, pedagogical practices which are shaped by the different nature of mathematical knowledge will be discussed based on the research question: how do mathematics teachers experience the nature of mathematical knowledge during their curricular and pedagogical practices? I interacted with four mathematics teachers who are teaching in different institutional schools in Kathmandu Metropolitan City, Nepal. Using the semi-structured and unstructured open-ended question(s), I explored their experiences on mathematics, mathematics curriculum and pedagogy. I used a methodology of phenomenology to explore the mathematics teachers' experiences on the nature of mathematics and pedagogical practices, in which the theory of knowledge constitutive interests (Habermas, 1972) guides the research for knowledge and implies concepts of others. The Habermas framework in this research proved to be useful for analyzing the nature of mathematical knowledge and pedagogical practices of mathematics teachers.

\section{Moving towards Nature of Mathematics}

Mathematics is defined as a definite body of knowledge and involves the study of quantity, structure, space, and change (Ndlovu, Pournara, \& Mwakapenda, 2019). On the other hand, mathematics is seen as a library of accumulated experiences, to be drawn upon and used by those who have access to it (Lerman, 1990). In this regards, there might be other researchers, mathematics teachers, and teacher educators who believe in both epistemological aspects which is discussed by Lerman (1990), and Ndlovu, Pournara, and Mwakapenda (2019). So, people might have different experiences and perceptions towards mathematical knowledge and its nature. The nature of mathematical knowledge is defined in various ways such as: the absolutist and fallibilist nature of mathematical knowledge (Ernest, 1991), pure, impure and im/pure nature of mathematical knowledge 
(Luitel 2013) and so on. Teachers' experiences of learning and teaching mathematics, beliefs towards mathematical knowledge, attending conferences, workshops or teacher training programs play an important role to construct different natures of mathematical knowledge. According to Ernest (1991), the absolutist view of mathematical knowledge consists of fixed, certain or unchangeable truths whereas, fallibilist view of mathematical knowledge consists of mathematical truth as fallible and corrigible and is always open for revision and change.

The nature of mathematics as a body of pure knowledge depicts authentic mathematics, thereby seeking for singularity, objectivity as well as universality whereas, impure knowledge portrays several types of mathematical knowledge systems arising from people's life world, such as embodied, informal, ethnic, artefactual and communal (Luitel, 2013). More especially, pure knowledge depicts finished products as well as already existing mathematical fact and disempower to construct mathematical knowledge whereas impure knowledge suggests that mathematical knowledge is embedded in our culture, day to day activities, thereby mathematical knowledge construction is an ongoing activity and constructed based on learners lived experiences. In this regard, pure mathematical knowledge enables learners to know mathematics in a global context and impure mathematical knowledge enables learners to see mathematical knowledge in the local context. By giving the value in both of the natures of mathematical knowledge, Luitel (2013) proposes that the nature of mathematical knowledge is im/pure which is inclusive of both pure mathematical knowledge and impure mathematical knowledge. Thus, im/pure nature of mathematical knowledge motivates teachers and students to access mathematical knowledge from multiple sources such as local and cultural traditions, global culture and practices, and so on. Further, Luitel (2013) mentions that the nature of mathematical knowledge as im/pure is to use conceive an inclusive, agentic, and multidimensional vision of mathematics education, with a view of rescuing mathematics education from the trap of elitism, unidimensionality, decontextualization and hegemony.

Furthermore, teachers having equal academic qualification may have different teaching strategies for which their teaching experiences and teacher professional development may matter a lot in their teaching career. For instance, one can teaches mathematics with the problem-solving orientation by making a connection with learners' experiences as well as daily activities, whereas, the other has a more didactic approach as a focus on scientific approach through the set of rules and axioms. In this context, Ernest (1994) mentioned that the teacher's view of the nature of mathematics, mathematics teaching and the process of learning mathematics matters a lot on teaching and learning mathematics. Indeed, teachers' philosophical as well as theoretical knowledge has a vital role on the way of pedagogical and curricular practices. In this scenario, Ernest (1994) pointed out three theoretical aspects on the nature of mathematics, namely; instrumentalist, Platonist and problem-solving that directly or indirectly affect teachers' beliefs, perceptions and experiences on their curricular and pedagogical practices. Instrumentalist focuses on determining cause and effect relationship, and learning and teaching mathematics align with task oriented problem solving aiming at finding correct answer (Mezirow, 1991). Furthermore, Platonist view of mathematics claims that mathematical knowledge is discovered but not created, whereas problem-solving view of mathematics communicate mathematics as a dynamic, human creation and invention; and mathematics is seen as a process of inquiry and coming to know but not a finished product (Ernest, 1994).

Both the teachers' and students' experiences towards the nature of mathematics directly or indirectly affect their teaching and learning mathematics. There are many workshops, activities as well as programs that have been conducted for the teachers to shift their experiences from one paradigm to another. There is a trend to represent the output of those training and workshops through research activity. For instance, Ndlovu et al. (2019) reported on findings from a study that explored perspectives of learners of grade 10 - 12 from two rural secondary schools in the Eastern Cape province in South Africa on the nature of mathematics prior to and at the end of a yearlong mathematics mentorship program. The researchers argued that the mentorship program led to positive shifts in learners' perspectives on the nature of mathematics. Moreover, based on the evidence of two research projects, Presmeg (2003) argued the beliefs that the students hold about the nature of mathematics enables and constrains their ability to construct conceptual bridges between familiar everyday practices and mathematical concepts taught in school or university. Similarly, Lloyd (2003) has pointed out that the teachers' beliefs can be changed based on experience with innovative curriculum materials and suggested for the need of greater attention to teachers' beliefs, experiences as well as perception about mathematics and mathematics curriculum. Similarly, Luitel and Pant (2019) argued that teachers' understanding of mathematics curriculum is different and it matters a lot to select the pedagogy. Constructing with interviews of mathematics teachers, they identified different images of mathematics curriculum namely, 
curriculum as a format for the textbook author, students' experience of learning, interactive process of teaching and learning, jack of all trades and masters of none. These images of mathematics curriculum reflect their understanding of the mathematics curriculum based on their curricular practices. These types of understanding of mathematics teachers' towards mathematics curriculum really affect teaching and learning mathematics either positively or negatively, and construct different natures of mathematics.

Similar to students, teachers' experiences towards the nature of mathematics might enable or constrain to the link between everyday mathematics and classroom mathematics. Further, teachers' as well as students' experiences towards the nature of mathematics is likely to play an important role to revise the mathematics curriculum, assessment tool as well as to make variation in pedagogy. In this context, I draw Ernest's (1991, 1994) and Luitel's (2013) orientations to explore the mathematics teachers' experiences on the nature of mathematics based on their curricular and pedagogical practices.

\section{Description of Participants}

This study has analyzed mathematics teachers' experiences towards the nature of mathematical knowledge based on their curricular and pedagogical practices. A purposeful selection method was chosen as recommended by several authors for this type of research in order to select information-rich cases for detailed study (Denzin \& Lincoln, 2000; Patton, 2002 as cited in Ajjawi \& Higgs, 2007). I have also followed the similar ways on the selection of participants. Further, Langdridge (2007) mentioned that a researcher may seek to recruit participants who have rich experiences to share. In this context, I have chosen the research participants based on their long experience of teaching mathematics and were from different ages and ethnicities. Thus, the participants of this study are four mathematics male in-service teachers teaching mathematics from grade six to nine for more than five years. Moreover, the participants of this study are master's degree students of mathematics education at one of the reputed universities of Nepal. They are selected from fifteen mathematics teacher students as the rest of them were full-time students and had no experience in teaching mathematics. I invited them in this study as research participants not perceiving them as master's degree students but perceiving them as experiences teachers teaching in institutional and public school in Nepal.

\section{Phenomenological Methodology}

Manen (1990) mentioned that conducting research means to question the way we experience the world, to want to know the world in which we live as human beings. Phenomenology encourages researchers to pose questions, interact, as well as communicate with the people who engage in their life worlds to explore their experiences. Phenomenology usually involves interviewing a small number of people, inviting them to talk about their experiences of a particular phenomenon, and analyzing the interview transcripts (Paley, 2017). Phenomenological research is designed to explore the participants' lived experiences regarding a certain phenomenon. Subscribing phenomenology in this study enabled me to explore the mathematics teachers' experiences on curricular and pedagogical practices. Phenomenology involves how people perceive an experience, a focus on life world, researcher does not enter the research process with a predetermined research hypothesis, although will have a general question that they wish to explore (Langdridge, 2007) and data text is analyzed based on the constructed themes.

Further, Trigwell (2000) mentioned that Phenomenology explores the varieties of experiences and understanding that people have a specific phenomenon, at a specific moment of time. While doing so, the outcome of the study is a set of unique and qualitatively different themes that explains the varieties of experiences. The themes of description emerge from the analysis of the participants' descriptions of their experiences of teaching mathematics. One of the aspects of exploring lived experiences and stories is to understand the meaning ascribed to experiences; thereby researchers, as well as readers, may gain an understanding of the meaning and perception of another person's world (Pascal, Johnson, Dore, \& Trainor, 2010). Indeed, understanding the experiences and perceptions of others' personal world related to the nature of mathematics based on curricular and pedagogical practices might enable people to shift education policy and their own practices from one paradigm to another which could be more inclusive in nature. In this context, as a qualitative researcher, my epistemological stand is subjective as participants expressed their experiences in multiple ways, comprising of their personal stories and experiences related to the mathematics curriculum and pedagogy as a form of knowledge.

Although, from the researcher's point of view, it is important to note how phenomenology as a research method has subscribed to the research and why this method is important rather than including the 
rudimentary definition of phenomenology. As I mentioned earlier, the purpose of this study was to explore the experiences on the nature of mathematics based on curricular and pedagogical practices of mathematics teachers. For this, I have conducted different unstructured as well as semi-structured interviews with mathematics teachers. For instance, I sought to know their experiences asking the questions like; being a mathematics teacher, how do you prepare yourself before going into the classroom? Could you please share your experiences regarding the use of the curriculum as a mathematics teacher? Further, the follow-up questions were: what is your understanding of the curriculum in general and mathematics curriculum in particular? Can you share your experiences of working with revised mathematics curriculum? and so on. Although my query related to their experiences on the nature of mathematics was depended on the way of their sharing of the previous question. Moreover, I spent with research participants more on discussing and sharing experiences of teaching mathematics in which I observed and evaluated as a researcher through the lens of the reviewed theory. Apart from this, I have collected their critical voices and lived experiences on curricular and pedagogical practices via mail communication which was easier to me to assess whenever I needed information throughout this research journey and was equally easier for my participants to respond to my query.

\title{
FINDINGS AND DISCUSSION
}

Here I share the experiences of mathematics teachers towards the nature of mathematics. Mathematics teachers doing master's degrees in one of the well-known universities of Nepal revealed their experiences based on their curricular and pedagogical practices. To fulfil the purpose of this study, I explored their lived experiences on the nature of mathematics embodying with them throughout the study. Being-with them was seen as a priori dimension of the self, which potentially supported me to understand and relate to others in all possible ways (Watts, 2001 as cited in Pascal et al., 2010). Ethically, I informed them about the purpose of discussion and did not use their actual names during the analysis of their experiences. Instead, I have used symbols such as T1, T2, T3, and T4 to represent the participants.

\section{Experiences towards Absolutism}

It was a very cold evening of January 2019, when I interviewed T1 in the university canteen with tea. He has been teaching mathematics for basic level students since he completed his intermediate level. At present he is also a master's degree student in mathematics education at one of the universities of Nepal. Firstly, I requested T1 to share his schooling experiences in brief. Secondly, he unpacked how he became a mathematics teacher and later he shared his curricular as well as pedagogical practices of mathematics. From our discussion, I came to know that he is the one whose interests and aim is not to be a mathematics teacher, rather, he was motivated to learn mathematics and tagged as a - 'talented student' during his schooling. He was guided in such a way that mathematical questions could have a significant role in other government jobs' examinations except for teaching. Further, T1 mentioned:

\begin{abstract}
...during my schooling, I was motivated to learn mathematics because I was oriented to questions related to mathematics that took an important place in the exam of different prestigious government jobs in Nepal. I never thought that I would be a teacher. However, I got the first or second position in the final examination of each grade, and I still remember helping my friends to solve mathematical problems. I was leveled as a brilliant and talented student. I thought that mathematics is about content, a set of formulas and rules which is fixed and it is for so-called talented students and will be helpful to get jobs in the future.
\end{abstract}

Indeed, many other mathematics teachers might have experienced the same as T1 had. Nowadays mathematics is regarded as a subject, content and has been taken as an important subject required for a bright future. Most of the mathematics teachers' answers to the questions: why do we solve the mathematical problem? Why do we need to memorize mathematical formulas? and so on were it is useful for the future, it develops memory power, thinking skills', and so on. In addition, students, teachers, even the parents and other stakeholders believe that mathematics consists of standard rules to govern mathematics around the world in the same way which is value-neutral and apolitical (Tutak, Bondy \& Admas, 2011). Similarly, the students who solved the algorithmic problems properly and memorized the formula thoroughly are leveled as talented, more intelligent people, no matter how they construct mathematical knowledge and apply it in their daily activities. Further, T1 added: 
...curriculum seems like static content. During my schooling, I didn't experience doing hands-on activities except for solving the bookish problems related to different topics of mathematics. My learning experience is likely to be dominated by my teaching, thereby usually recommending textbooks' readymade problems, practice books, having more certain mathematical problems to be solved.

In fact, as mentioned by T1, our experiences are being superior in our teaching. It is because of lack of enough TPD program, lack of awareness, same curriculum, and content for many years, marks and rank oriented assessment, and so on , thereby many mathematics teachers in Nepal try to impose their own previously gained experiences in the classroom. As T1 said that there might be other mathematics teachers who still believe in the curriculum as likely to have fixed content to be taught and promotes textbook-based teaching. For many learners as well as teachers, text-books are key elements in both mathematical teaching and learning, and there is evidence that reliance on the textbook can be a feature of classroom practice (Macintyre \& Hamilton 2010). Textbook oriented teaching likely to constrain the bridge between everyday mathematics and school mathematics which might be promoting the Platonist view of mathematics. For Platonists, "mathematics is neither a formal and meaningless game nor some kind of language less mental construction, but a science, a public discipline concerned to discover and validate objective or logical truths" (Rotman, 2006, p. 101). Students' experiences and prior knowledge could be neglected during teaching and learning in which the maximum problems included in the textbooks are not as per our context. In this context, Luitel (2012) has expressed his experience in mathematics as a vehicle for enhancing scientific and technological innovation by subscribing to a narrowly conceived notion of reform as simply adding more content areas in the curriculum in the name of curriculum revision. Arriving at this stage, I argue that the content oriented curriculum enables teachers to select the teacher-centered pedagogy which is likely to ignore students' prior knowledge and experiences. Regarding this T1 added:

...I usually make plans as well as choose pedagogy based on the nature of the content and mathematical problems. I orient students to do the same mathematical problems based on specific rules and formulas if necessary, which is important from the examination point of view until they get memorized.

Here the statement of T1 likely to promote the view 'practice makes a man perfect' is still dominant in the mathematics classroom. The common answers given by the mathematics teachers to the maximum questions regarding the way of understanding of particular problems raised by the students is to practice until one gets memorized or until s/he knows the process or steps of solving specific problems. Moreover, such approaches are an intention to control mathematical activity as well as problem-solving via sets of manageable and instrumental actions which are likely to promote the Instrumentalist view of mathematics. Instrumentalism is the tendency to look upon everything as tools to reach another goal or end Varkoy, 2007). Thus, instrumentalism promotes mastery by practice, memorization or repetition to prepare for the exam. This kind of process is also called instrumentalist trend in mathematics education. Next day, in the similar setting, T2 agreed with $\mathrm{T} 1$ on the issue discussed above and further added:

\begin{abstract}
...most of the teachers, head teachers as well as parents are keen to know how their kids can secure good marks in exams rather than to know how mathematics learning can be made meaningful. The curriculum became the prescribed document that nobody shows interest in using it and is similar to practice. I usually tell them to practice and memorize the selected mathematical problems which are important from the examination point of view, and I have been experiencing such practice since the beginning of my teaching career.
\end{abstract}

As experienced by $\mathrm{T} 1$ and T2, the pedagogical practice of mathematics in many schools of Nepal seems to be guided by banking pedagogy discussed by Freire (1996), in which teachers become active lecturers and students become the passive listener and likely to promote the one size fits all approach. Frere pointed out that teachers tend to use banking pedagogy in which they fill students' minds as containers with the knowledge that someone has determined they need to know (Tutak, Bondy, \& Adams, 2010). Banking pedagogy constrains thinking of the students from the cultural perspectives and allows them as passive receivers of knowledge. Moreover, curriculum is seen as a product that is delivered, rather than can actively and flexibly be developed by the teacher or students (Fraser \& Bosanquet, 2006). The product-oriented mathematics curriculum seems to be static, fixed, unchangeable and prescribed in nature, which has been rooted in some of the school settings in our context. However, teacher-centred pedagogy such as banking 
pedagogy as discussed above discourages students from learning mathematics and may pose different epistemological questions on its applicability. In this regard T2 added:

...I found the belief of Nepali students towards mathematics is still conventional, they think it just as a mental exercise. While teaching mathematics for a decade, many of my students asked questions like Sir, what is the implication of this mathematics in our real life? What is the implication of algebra in our life? and so on.

These are some common questions raised by the students that I have also experienced during teaching and learning mathematics. This might happen because of the prescribed nature of mathematics curriculum which leads teachers to promote solving universal fixed and pure mathematical content. Supporting this argument, T2 again reflected

\begin{abstract}
... expert-driven prescribed curriculum, heavily content loaded mathematics textbook, marks oriented society, are the main reasons to take mathematics itself as a difficult and jumpy nature and it increases math phobia to students.
\end{abstract}

Taking reference to the argument of T2, I argue that jumpy nature as well as leveled as difficult subjects discourage students to learn mathematics, which might be the reason for low achievement and low participant level in learning mathematics as compared to other subjects. As a result, we may have to face different challenges after a few years as mentioned by educators, different researchers, and mathematicians. For instance, Macryine and Hamilton (2010) argued that one of the challenges for policymakers and educationalists today (or in the future) is to increase participation level and success rates on study of mathematics. So, curriculum materials such as text-books, practice books, guides, and so on may rarely promote students to link mathematics in context and encourage students as well as teachers to think mathematics as abstract and pure knowledge and also increase math phobia as guided by technical interest of Habermas.

\title{
Technical interest and absolutist nature of mathematics
}

The above discussion enables me to move towards the technical interest of knowledge construction as discussed by Habermas (1972). According to Hebermas (1972), the basic orientation of technical interest is towards controlling and managing the environment. The role of the teacher is to control students by imposing the algorithmic problems to be solved, formulas and set of rules to be memorized, which could be based on prescribed mathematics curriculum or heavily content loaded mathematics textbook. Mathematical knowledge is generated and produced through experimentation.

In our context, for many teachers, experimentation in mathematics seems to be solving bookish mathematical problems applying certain rules and steps and checking whether the answers are correct or wrong as given in the mathematics textbook. Similarly, curriculum designers, textbook authors, and even university professors have common opinion that the school curriculum needs to introduce more content so as to make students as competent as their international counterparts (Luitel, 2012). These types of opinions are likely to be guided by pure knowledge (Luitel, 2012). Absolutist nature (Ernest, 1991) of mathematics promote pure content-based mathematics rather than making them context-based, algorithmic problem-solvers rather than making real-life problem solvers, the objectivity of mathematical knowledge rather than promoting subjectivity of the students' mathematical knowledge.

Moreover, Hua (2015) mentioned that teacher-oriented by technical interest sets the subject and the student is set as the object, the educational process is degraded as the teacher controls and disciplines students' minds by fixed and absolute knowledge transmission. I have also experienced as experienced by T1 and $\mathrm{T} 2$ that in our context where the teacher is considered as superior who can impose everything on the students regarding them as empty minds. Arriving at this stage, the nature of mathematics as absolutist (Ernest, 1991) and Pure (Luitel, 2012) are likely to have a similar orientation guided by technical interest as experienced by T1 and T2. In this context, I also agree with Lerman (1990) as he has mentioned that mathematics is seen by most people, and by most practicing mathematicians, teachers in particular, as the paradigm of knowledge: certain, absolute, value-free and abstract.

\section{Experiences towards Fallibilism}

It was a day of January 2020 , the sky had a hazy shade of winter and it was likely to be cold weather. The day, I had earlier called two mathematics teachers (T3 and T4) in the university's canteen for interaction and 
to have coffee together. Both of them have long experiences of teaching mathematics from primary to secondary level. T3 and T4 have been teaching mathematics for basic level students since 2010 and 2012 respectively. With a long experience of teaching mathematics at different institutional schools, T3 served at one of the government schools for two years as a Teach For Nepal (TFN) fellow. In addition, both of them are Master's degree students of mathematics education at one of the universities of Nepal. Initially, T3 never thought that math as education; instead for him, mathematics is content to be learned and rules to be followed, formula to be memorized, where humanity, ethics, sympathy, empathy, culture, and are isolated from the content, rules, and formulas. Now he believes that he has grown academically as well as professionally. Hence, he is trying to shift from the conventional curricular or pedagogical practices to the progressive ones. T3 further stated:

\begin{abstract}
...mathematics is embedded in our cultural practices. Mathematics has an important role in order to reform our daily works in a systematic and scientific way. Thus, mathematics for me is a study of patterns, real-world problem-solving. I am convinced with the concept that mathematics is not only solving algorithmic problems to be solved following certain rules and specific steps but also is an education that helps to solve real-world problems through communication, negotiation and so on.
\end{abstract}

Arriving at this stage, I conceptualize his thoughts towards mathematics as social practice constructed by human beings. The way of understanding might be different and practice could be modified as per the human needs, experiences as well as value. In this context, I agreed with Lerman (1990) who has mentioned that mathematics is seen as a social construction, its results are relative to time and place, and subject to revolutionary change as much as other forms of knowledge. Moreover, T3 gives a value to mathematics curriculum rather than to a mathematics textbook during planning and teaching. In this respect he mentioned:

...I sometimes dismiss the mathematical content given in the textbook which is not mentioned in the curriculum. Following the national mathematics curriculum enables me to know the content to be taught but, I introduce those contents on the basis of students' experiences, culture, activity which is not clearly defined in a prescribed mathematics curriculum. So, for me, the mathematics curriculum is a dynamic text in which teachers need to get an opportunity to revise as per the specific needs and interests of students as well as their experiences even though it is perspective in nature.

At the same time, he showed his dissatisfaction with the present official mathematics curriculum stating that it has been isolating the students and teachers. He shared one of the examples (given below) guided by culture, pattern as well as nature, which he mentioned while revising the curriculum himself before lesson planning

T3: Do you know honey bees also follow mathematical design and shapes?

Students: What? How? Where did they learn from?

T3: When honeybees design their hive they use hexagonal shapes to store their honey as hexagonal shapes cover less area and can store maximum amount of honey. This helps them to survive in the winter season. Not only this, every nerve on leaves is designed in pattern. This is in sequential order. The distance between two nerves is always the same distance.

Listening to T3's experiences towards curricular and pedagogical practices of mathematics really made me thoughtful. It was new for me and as a mathematics teacher, teacher educator as well as researcher, it became an eye-opener discussion. It looks like students become active participants in his class in which they are actively engaged in discussion by raising critical questions and sharing experiences rather than becoming passive listeners. If we promote and add these types of relationships between mathematics and nature then, obviously students can realize that mathematics is our basic need of life.

Moreover, the curricular and pedagogical practice of T3 likely serves the theoretical idea of ecological consciousness as mentioned by Luitel and Taylor (2008) which helps to promote the contextual practices of mathematics education. "The idea of ecological consciousness promotes post-human thinking by recognizing the relationship between humans and other species, plant, and land as neighbors engaged in reciprocal relationships; a view that can characterize a Nepali Cultural Worldview (NCW) which comprise diverse 
linguistic practices, as well as Vedic, Buddhist and other indigenous faith systems beings, practiced in Nepal" (Luitel \& Taylor, 2008 p. 3). At the same time, another participant T4 also agreed with T3 and mentioned that:

... at the beginning of the academic year, I myself with the collaboration of other teachers worked with the national curriculum (design?) and was revised on the basis of schools as well as student's cultural practices, experiences, materials, and so on . So, before going to the classroom, I go through the lesson plan prepared on the basis of the revised mathematics curriculum. I always try to introduce the mathematical concepts through ICT tools and software (such as PowerPoint, Geogebra, Google Sketch-up, and so on) in this digital age, in which students get motivated to learn mathematics.

However, both T3 and T4 are not satisfied with the present practices of curriculum development. It is likely to be the desk-based approach of curriculum development as developed by comprising the maximum view of the so-called experts. Both the teachers T3 and T4 accept the multicultural approach of curriculum development and teaching, which focuses on various local cultural mathematical knowledge and globally practiced mathematical knowledge. Yet, the policy provision of local curriculum and the use of locally available resources for teaching and learning have continuously lost its position in the education circle (Wagle, Luitel, \& Krogh, 2019) which become extremely sad moments for those teachers who try to shift from the conventional approach of teaching to progressive. Arriving at this stage, as a researcher I have conceptualized the experiences of T3 and T4 by fallibilist nature of mathematics discussed by Ernest (1994) as im/pure nature of mathematics as discussed by Luitel (2012) and oriented by practical interest and to some extent emancipatory interest as discussed by Habermas (1972).

\section{Practical interest and fallibilist nature of mathematics}

Hebarmas (1992) mentioned that the orientation of technical interest is towards control but of practical interest is towards understanding and meaning-making. Inclusiveness is another aspect of practical interest. Here, the role of the teacher is to create an environment where students can easily share their experiences, actively participate in the group work and activity, problem-solving without fear and mathematical anxiety as experienced by T3 and T4 which is likely to promote the fallibilist as well as im/pure nature of mathematics. Ernest (1991) mentioned that the fallibilist nature of mathematical knowledge is corrigible and perpetually open to revision. Thus, fallibilist nature encourages mathematics teachers to study mathematics from various dimensions such as local and global cultural dimension of mathematics which helps them to incorporate the local as well as global mathematical practices inside the classroom, thereby students become locally as well as globally competent. Fallibilist nature of mathematics brings with it the implication that mathematics is culture-laden and value-laden (Lerman 1990). In addition, as per the fallibilist nature of mathematics, mathematics curriculum should not be static but open to revision as revised by T3 and T4 before going to the classroom as per the specific needs and interests of learners. It must be developed with the presence of students or teachers rather than so-called experts.

According to Hua (2015), teachers who are guided by practical interest can succeed to maintain an educative relationship between teachers and students as well as teachers and their colleagues with mutual understanding. On the one hand, everyone such as teachers, students, and other stakeholders put their opinion without fear. On the other hand, they respect each and everyone's thoughts. Students can learn and enjoy the embodiment of local as well as global wisdom such as freedom of expression, togetherness, happiness, sense of friendship, and so on. Through mathematical games, collaborative activities and real world problem solving and so on. Moreover, oriented by practical as well as emancipatory interest likely to enable mathematics teachers to excavate many mathematical knowledge systems embedded in villagers' daily practices across the country and helps to develop strong contextualized pedagogical perspectives to serve the diverse interests and aspirations of Nepali children (Luitel \& Taylor, 2007).

\section{CONCLUSION}

The above discussion shows that the experiences of mathematics teachers towards mathematics curriculum and pedagogy are different. Some of the experiences are rooted in the absolutist nature of mathematics with pure and fixed mathematical content and others are rooted in the fallibilist nature of mathematics, which is likely to be similar to the im/pure nature of mathematical knowledge. Nepal, which hosts more than 124 distinct languages and diverse cultural traditions, more than one hundred different 
ethnic groups and many of them have rich mathematical practices in their day to day practices. In this scenario, the absolutist nature of mathematics might not serve students' needs, interests and the experiences. Instead of motivating and encouraging students, absolutist nature of mathematical knowledge might discourage and demotivate the students to learn mathematics.

It is necessary to motivate and encourage students in mathematics. School curriculum needs to incorporate the value of their cultural practices, experiences as well as prior knowledge based on classroom activities. Mathematics curriculum must be created a place for students as well as teachers to practice based on their prior knowledge and experiences, reflect critically, challenge the status quo and so on. Therefore, in my opinion, knowledge constructed through practical as well as emancipatory interest might help to make mathematics curriculum and pedagogical practices more context based, students as well as teacher friendly rather than mathematics curriculum guided by technical interest. Emancipatory interest focuses on emancipation and empowerment to engage students as well as teachers in autonomous action arising out of authentic, critical insights into the social construction of human society (Grundy, 1987). Thus, the curricular as well as pedagogical practices guided by emancipatory interest might enable students as well as teachers to involve in critical self-reflection towards existing practices rather than simply solving routine and algorithm mathematical problem, thereby might came up with more inclusive and democratic practice. Moreover, curriculum guided by emancipatory interest promotes counter-hegemonic vision of teaching and learning mathematics and might develop critical consciousness. Critical consciousness embedded mathematics curriculum helps students and teachers to unpack the cultural nature of mathematics education taken-forgranted assumptions about teaching and assessment through critical pedagogy.

Furthermore, it might be better to develop the concepts of different mathematical contents via examples of the local practices, aiming at understanding and meaning making, which is needed to address through mathematics curriculum. It does not mean to neglect the mathematical contents which are also practiced in other countries but to introduce those contents from real-life examples and applicability. Similarly, it is important to change the beliefs of society towards mathematics as abstract, difficult as well as far from human language, culture and day to day practices. At the same time, the teacher should have the willingness to update himself/herself on the basis of time and context. The TPD program should be conducted on the basis of teacher's needs and context rather than making commercial and profit oriented. At the same time, awareness programs for parents are needed to make them aware of the fact that mathematics is not isolated subjects from other fields and not always the topic to be discussed related to the examination and marks. It can be concluded that mathematics curriculum should be flexible and must have the right to the schools' mathematics teachers and students to revise it based on the schools' context, students' experiences, cultural diversity, and so on. In addition, teachers' and students' participation during curriculum planning and designing is very important to motivate students as well as enhance their creativity, critical thinking and imagination.

\section{ACKNOWLEDGEMENTS}

This article is based on the small scale phenomenological inquiry conducted as part of the Online Writing Program - Accountability Writing Group 2019-020, Nepal, conducted by associate professor, Shyam Sharma, Stony Brook University, Stony Brook, USA and associate professor, Prem Phyak, Tribhuvan University, Nepal. I am thankful to our facilitators for their immense support, guidance, inspiration and continuous encouragement to complete this article. I am equally thankful to the participants of the program for their queries and valuable suggestions.

\section{Disclosure statement}

No potential conflict of interest was reported by the author.

\section{Notes on contributors}

Laxman Luitel - Kathmandu University School of Education, Nepal.

\section{REFERENCES}

Dossey, J. (1992). The nature of mathematics: Its role and its influence. In D. A. Grouws (Ed.), Handbook of research on mathematics teaching and learning (pp. 39-48). New York: Macmillan. 
Ernest, P. (1991). The philosophy of mathematics education. London: Routledge.

Ernest, P. (1994). The impact of beliefs on the teaching of mathematics. In A. Bloomfeild, \& T. Harries (Eds.), Teaching and learning in mathematics. Derby: Association of Teachers of Mathematics.

Fraser, S. P., \& Bosanquet, A. M. (2006). The curriculum? That's just a unit outline, isn't it? Studies in Higher Education, 31(03), 269-284. https://doi.org/10.1080/03075070600680521

Freire, P. (1996). Pedagogy of the oppressed (revised). New York: Continuum.

Grundy, S. (1987). Curriculum: Product or Praxis? London: Falmer.

Habermas, J. (1972). Knowledge and Human Interests (2nd Ed.) London: Heinemann.

Hua, (2015). On teacher development. In W. Pinar \& Z. Hua (Eds.), Autobiography and teacher development in China: Subjectivity and culture in curriculum reform. Springer. https://doi.org/10.1080/13664530.2015.1049748

Langdridge, D. (2007). Phenomenological psychology: Theory, research and method. Pearson Education.

Lerman, S. (1990). Alternative perspectives of the nature of mathematics and their influence on the teaching of mathematics. British Educational Research Journal, 16(1), 53-61. https://doi.org/10.1080/0141192900160105

Lloyd, G. (2002). Mathematics teachers' beliefs and experiences with innovative curriculum materials. In Beliefs: A hidden variable in mathematics education? (pp. 149-159). Springer, Dordrecht. https://doi.org/10.1007/0-306-47958-3_9

Luitel, B. C. (2013). Mathematics as an im/pure knowledge system: Symbiosis, (w)holism and synergy in mathematics education. International Journal of Science and Mathematics Education, 11(1), 65-87. https://doi.org/10.1007/s10763-012-9366-8

Luitel, B. C. (2018). A mindful inquiry towards transformative curriculum vision for inclusive mathematics education. Learning: Research and Practice, $4(1), \quad$ 78-90. https://doi.org/10.1080/23735082.2018.1428141

Luitel, B. C., \& Taylor, P. C. (2005, Apr). Overcoming culturally dislocated curricula in a transitional society: An autoethnographic journey towards pragmatic wisdom. Paper presented at the annual meeting of the American Educational Research Association (AERA).

Luitel, B. C., \& Taylor, P. C. (2007). The shanai, the pseudosphere and other imaginings: Envisioning culturally contextualised mathematics education. Cultural Studies of Science Education, 2(3), 621-655. https://doi.org/10.1007/s11422-007-9068-7

Luitel, B. C., \& Taylor, P. C. (2008) Globalization, ecological consciousness and curriculum as montage: A vision for culturally contextualized mathematics education. In: 16th Annual Conference of the Southern African Association for Mathematics, Science and Technology Education (SAARMSTE) 2008, 14-18 January 2008, Maseru, Lesotho.

Luitel, L., \& Pant, B. P. (2019). Images of mathematics curriculum held by mathematics teachers: mapping the road for transformative pedagogy. In Y. Rahmawati \& P. C. Taylor (Eds.), Empowering Science and Mathematics for Global Competitiveness: Proceedings of the Science and Mathematics International Conference (SMIC 2018), November 2-4, 2018, Jakarta, Indonesia. CRC Press. https://doi.org/10.1201/9780429461903-69

Macintyre, T., \& Hamilton, S. (2010). Mathematics learners and mathematics textbooks: a question of identity? Whose curriculum? Whose mathematics? The Curriculum Journal, 21(1), 3-23. https://doi.org/10.1080/09585170903558224

Mezirow, J. (1991). Transformative dimensions of adult learning. San Francisco, CA: Jossey-Bass. https://doi.org/10.1177/104515959100300116

Ndlovu, W., Pournara, C., \& Mwakapenda, W. (2019). Changes in learners' perspectives on the nature of mathematics after participating in a mentorship programme. African Journal of Research in Mathematics, Science and Technology Education, 23(1), 111-121. https://doi.org/10.1080/18117295.2019.1601930

Paley, J. (2017). Phenomenology as qualitative research: A critical analysis of meaning attribution. Routledge. https://doi.org/10.4324/9781315623979

Pinar, W. F. (2004). What is curriculum theory? Routledge. 
Presmeg, N. (2003). Beliefs about the nature of mathematics in the bridging of everyday and school mathematical practices. In Beliefs: A hidden variable in mathematics education? (pp. 293-312). Springer. https://doi.org/10.1007/0-306-47958-3_17

Spangenberg, E. D., \& Myburgh, C. (2017). Comparing South African Female and Male Pre-Service Teachers' Beliefs about the Nature of Mathematics. Africa Education Review, 14(2), 140-155. https://doi.org/10.1080/18146627.2017.1292828

Trigwell, K. (2000) Phenomenography: discernment and variation. Improving Student Learning, 7, 75-85.

Van Manen, M. (1990). Researching lived experience: Human science for an action sensitive pedagogy. Albany, NY: State University of New York Press

Wagle, S. K., Luitel, B. C., \& Krogh, E. (2019). Irrelevance of Basic School Education in Nepal: An AntiColonial Critique on Problems and Prospects. Dhaulagiri Journal of Sociology and Anthropology, 13, 31-39. https://doi.org/10.3126/dsaj.v13i0.24032 